\title{
Geoffrey Samuel: An Introduction to Comparative Law Theory and Method. Hart, Oxford and Portland, Oregon, 2014.
}

\author{
BALÁzs FeKETE*
}

There has been a growing general interest in comparative law during the last ten years. Many new books have been published in this period and the volumes of Mathias Siems, ${ }^{1}$ Jaakko Husa ${ }^{2}$ or Günther Frankenberg ${ }^{3}$ serve as good examples to illustrate this trend. There is a common aspect that connects the work despite the apparent and obvious differences amongst these authors' vision on comparative law. Each Author intended to approach the domain of comparative law with a fresh outlook.

This strong intent to find and pave novel ways in the theory and practice of legal comparison that may be able to fit much better the new challenges of the globalized world led these contemporary authors to integrate many new components into the conventional framework of comparative law. They extended the scope of comparative law to such new areas - for example - as human rights narratives, ${ }^{4}$ the application of statistical methods, ${ }^{5}$ and legal evolution. ${ }^{6}$ This transformation in interest even had an impact on the disciplinary self-reflection of comparative law. Consequently, the discussion of disciplinary and methodological issues has become a surprisingly important place in this new discourse as compared to the relevance of these kinds of questions in the earlier, classic literature. 'Something' has been happening around comparative law nowadays and has had an intensive repercussion even on the theory and methodology of comparative law.

The volume of Geoffrey Samuel, professor of law at the Kent Law School and former visiting professor of various European law schools, published in 2014, definitely fits into this stream of 'new' comparative law. It is different to some extent as its primarily target was law school education with special regard to those postgraduate students who are required to use the comparative law methods in their research activities. ${ }^{7}$ Thus, in essence, this book was originally intended to become a university research manual as for the application of comparative law methods. Nonetheless, and this is the core point of this book review, Samuel's volume cannot simply be considered as one of the conventional course or text books for students. It deserves a place in recent comparative law literature in its own right due to its elaboration and scholarly quality. It is worthy of being regarded as one of the leading manuals on comparative law methodology although it was originally prepared for students.

* Research fellow MTA-TK-JTI Budapest, senior lecturer ELTE-ÁJK Budapest. E-mail: Fekete.Balazs@tk.mta.hu. This article was prepared with the support of the Bolyai scholarship.

1 Siems (2014).

2 Husa (2015).

${ }^{3}$ Frankenberg (2016).

${ }^{4}$ Frankenberg (2016) 167-203.

5 Siems (2014) 146-87.

${ }^{6}$ Husa (2014) 241-52.

7 Samuel (2014) preface. 
This book is composed of an Introduction, a Conclusion and ten chapters. The first three chapters, Problems and Promises of Comparative Law; Asking the Right Question, What is 'Comparison'?, tackle the basic questions of scholarly research in comparative law. The author, here, introduces the readers, prominently research students, to some elementary questions that cannot be avoided when deciding to begin a research project in law with a comparative scope. An impressive point of the first introductory chapter is that Samuel did not hide the various uncertainties around comparative law. On the contrary, he emphasizes at various points that an academic consensus has been lacking in many basic questions. For instance, the role of theory in legal comparison is still debatable and there are various pro and con arguments with respect the inclusion of theory in comparative law. ${ }^{8}$ Chapter 2 familiarizes the readers with the general 'know-how' of how to prepare research designs in comparative law studies. The central topic of this chapter is the problem of formulating a proper research question that has a prominent relevance in a successful comparative study due to the inherent methodological complexity. The third chapter in this introductory section addresses the basic tenets of applying the comparative law methods in legal scholarship. All the main approaches of doing legal comparison, construction of models, epistemological questions behind comparison, the difference between macro and micro comparison, the role of difference in doing comparative law, the use of either genealogical or analogical perspectives, and the importance of the internal and external perspective, are discussed by the author and these methodological mosaic pieces offer excellent starting points for the future research activities. In addition, this methodological mosaic is also able to map the main lines of the contemporary methodological discourse.

The next four chapters may be regarded as the backbone of the volume. In these, Samuel discusses the most frequently applied methods of recent comparative law. As the first step, he provides a concise and critical overview of functionalism in Chapter 4 and 5. One of the novelties of Samuel's understanding that he puts the functional method into a broader context by arguing that it can also be regarded a possible scheme of intelligibility in social sciences. The presentation of other schemes of this kind, namely structuralism, casual analysis, hermeneutical analysis, and actional analysis really helps the reader to understand better both functionalism in comparative law as such and its inherent methodological limits. In order to open up new methodological orientations, Chapter 6 focuses on the application of structural approaches in comparative law. Samuel explains the basic tenets of structuralism in legal scholarship empathically and welcomes the idea of Catherin Valcke about applying systems theory in comparative legal studies ${ }^{9}$ but he also formulates some doubts. For instance, it is argued by Samuel that any structural comparison may be endangered by the 'introspective bias' of the comparativist who may try to rely on their own legal concepts when understanding another legal structure e.g., a national legal order or a legal family, with a different conceptual background. The last component of this methodological section is Chapter 7. Most of the readers would expect the presentation of the 'cultural' method, or 'cultural comparativism'10 but Samuel does not use this term. Instead he refers to the hermeneutical method in this chapter. ${ }^{11}$ This slightly unconventional terminology is due to the scholarly position of Samuel arguing that comparative law

8 Samuel (2014) 19-20.

9 Samuel (2014) 106.

10 Cf. Siems (2014) 98-104.

11 Interestingly, Van Hoecke does not use the term cultural method either but refers to the 'law in context' approach. See Van Hoecke (2015) 16-18. 
methods represent different schemes of intelligibility and the hermeneutical method is one of these schemes. There has been a considerably methodological flux around the term of 'culturalism' in the contemporary literature ${ }^{12}$ so the omission of this term is to be supported. In essence, the chapter discusses Pierre Legrand's theses on the necessity of an empathic approach in comparative law that is focused on difference in place of similarity and also reflects on the concept of legal mentality leading the research towards the 'deep structures' of legal orders. All in all, these methodological chapters, from Chapter 4 to 7 , draft the recent methodological alternatives in comparative legal studies in very clear way. In addition, the author, where necessary, also highlighted the problematic points and explained the criticism.

The next two chapters, Chapter 8 and 9, focus on the other main issue of legal comparison, besides the apparent methodological diversity: the object of comparison, the law. The problem of the concept of law as applied by the comparativists has frequently been overlooked because of the constant debates around methodological questions. However, Samuel also points out the relevance of this issue. He starts with the presentation of the most widely shared 'rule model', as the core of law as phenomenon, than by revealing the weaknesses of this model Samuel introduces alternative approaches i.e., the realist model, the role of mentalities, the problems of legal conceptualization, in order to emphasize the complexity of the issue. In addition, the basic tenets of such influential thinkers as Hans Kelsen, Herbert Hart, and Ronald Dworkin are also discussed to highlight other dimensions of complexity when trying to conceptualize law. As a conclusion, Samuel draws attention to the utmost importance of sensitivity towards different conceptions of law when doing comparative law as without this the application of a given concept may seriously mislead the entire research.

The last chapter discusses the 'paradigm contexts' of comparative law methodology. Samuel argues that the schemes of intelligibility in comparative methodology can only properly be understood if the researcher becomes capable of identifying the basic features of their contexts, the paradigms in which they are embedded in each case. Besides other paradigm orientations, the 'cultural paradigm' is also discussed as the context of the hermeneutical method here. Samuel points out that this paradigm has some inherent risks as for research activities by criticizing Legrand's culturally inspired theory of legal comparison. Firstly, the overemphasizing of culture and, thereby, the prominence of uniqueness of each individual legal culture may impede the creation of syntheses backing most of the comparative legal studies. Secondly, the, taken as granted, presumption that only individual macro legal cultures exist, for instance Common Law or Civil Law, may conceal the internal plurality of the legal cultures built up from sub and counter cultures. All in all, this chapter explains well the insight that methodological concerns cannot be isolated from the broader, dominantly philosophical contexts and sheds light on the most relevant points.

Samuel synthesizes all the previous inquiries in the conclusive part. It is argued that the main points of a comparative law research agenda can be summarized in a list of ten methodological dichotomies: 1. comparison and law; 2. macro and micro comparisons; 3. similarity and difference; 4. genealogical and analogical comparison; 5. internal and external perspectives; 6. functional method and its alternatives; 7. rule-model and its alternatives; 8. nature and culture; 9. holism and individualism, 10. actual and virtual facts. In conclusion, Samuel stresses that each comparative law research design must start with 
making decisions with respect to dichotomy no. 1 . That is, the comparativist always has to find adequate answers to two elementary questions when drafting a research plan: "what is meant by 'comparison', and what is meant by 'law'."13 The other methodological choices are largely the consequences of these basic decisions.

Samuel's book may be praised from various aspects. First of all, its scholarly clarity has to be mentioned. The language of the chapters is easy to follow although rather abstracts and philosophical issues are at stake many times. It is certainly able to fulfill its main objective; students interested in comparative legal studies will certainly use it as a main point of reference as for methodological problems. Secondly, its methodological pluralist attitude seems to be one of its main advantages. Samuel does not want judge the appropriateness of older or newer methods and approaches once and for all, but he intends to present all of them in an empathic and critical manner. Thus, Samuel leads the reader through the advantages and disadvantages, certainties and uncertainties of the various tools of comparative legal research with a neutral attitude. Lastly, Samuel's point that comparative law has no single method but a set of various methodological perspectives exist that may vary according to the nature of the problem studied should be welcomed. In his own words: "There is no single theory, no single paradigm or programme, no single scheme of intelligibility and no single reasoning method in the social sciences. As this book has attempted to show, the same is equally true of comparative law studies." 14 In summary, Samuel reveals that the methodological plurality and uncertainty, inherent in comparative legal studies, is certainly not a deficiency, but it is better to consider it as a source of inspiration and motivation.

\section{LITERATURE}

Frankenberg, Günther, Comparative Law as Critique (Edward Elgar 2016).

Husa, Jaakko, A New Introduction to Comparative Law (Hart 2015).

Samuel, Geoffrey, An Introduction to Comparative Law Theory and Method (Hart 2014).

Siems, Mathias, Comparative Law (Cambridge University Press 2014).

Van Hoecke, Marc, 'Methodology of Comparative Legal Research' (2015) december Law and Method $1-35$.

Withman, James Q., 'The Neo-Romantic Turn' In: Legrand, Pierre, and Munday, Roderick (eds), Comparative Legal Studies: Traditions and Transitions (Cambridge University Press 2003).

13 Samuel (2014) 173.

14 Samuel (2014) 179. 